Research Square
Preprints are preliminary reports that have not undergone peer review.

They should not be considered conclusive, used to inform clinical practice, or referenced by the media as validated information.

\title{
Therapeutic Exercise to Improve Motor Function Among Children with Down Syndrome Aged 0 to 3 Years: A Systematic Literature Review
}

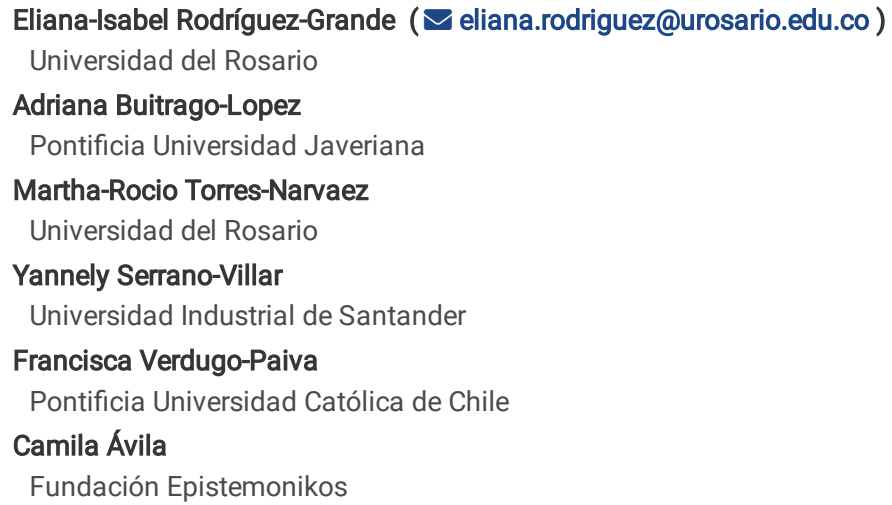




\section{Abstract}

Objective: To determine the effect of therapeutic exercises on the motor function of children with Down syndrome (DS) aged 0 to 3 years.

Data Sources: A search was carried out on PubMed, PEDro, EMBASE, SCIELO, Lilacs, Cochrane library without publication date restrictions for the terms.

Study Selection: The search yielded 1384 eligible articles, which were screened by 2 reviewers. RCTs that would have evaluated the effectiveness of therapeutic exercise were selected, and that would have reported the effectiveness in the outcomes.

Data Extraction: The methodology and results of the studies were critically appraised in compliance with the Preferred Reporting Items for Systematic Reviews and Meta-Analyzes guidelines.

Data Synthesis: Six studies were included. Two types of therapeutic exercises, aerobic and neuromuscular, were identified. A therapeutic aerobic exercise was performed using the treadmill, while a neuromuscular exercise was done using unstable surfaces. The exercise frequency ranged from three days to five days

a week, and the duration of each session was between six and 15 minutes.

Conclusion: There is moderate to high evidence to support that therapeutic exercise promotes the occurrence of motor patterns such as gait patterns and enhances the motor skills of children with DS aged 0 to 3 years.

\section{Introduction}

Down syndrome (DS) in children triggers musculoskeletal and intellectual disorders, which in turn impact motor function. This function encompasses the set of motor skills whose execution can be observed and measured in terms of orientation, displacement, speed, and acceleration and also includes coordinated and intentional actions that are part of the child's daily interactions, such as crossing obstacles and walking over irregular terrains. The motor function also includes those internal processes associated with practice, experience, and the context in which movement develops, which enable the learning process needed to acquire a specific motor skill ${ }^{1-3}$.

The acquisition of gross and fine motor functions in children with DS is different compared with that in typically developing (TD) children, mainly due to the level of development of the central nervous system, hypotonia, the presence of primitive reflexes, and joint hypermobility $2,4,5$. Children with DS generally start walking around age 3 and have a limited performance regarding balance, hand-eye and foot-eye coordination, and the speed at which they can execute fast movement patterns, such as jumping or kicking. This leads to difficulties in developing activities of daily living ${ }^{4,6}$ and poses a challenge for their caregivers, considering that only $11.6 \%$ of 5 -year-old children with DS can brush their teeth and $0 \%$ can tie their shoes ${ }^{6,7}$.

Children with DS require health care plans that promote a better motor skill performance and that include therapeutic interventions, such as therapeutic exercises. Therapeutic exercise is a physical activity that can be measured accurately and responds to therapeutic objectives according to the patient's condition. Physical exercise applied to the clinical setting contributes to promoting, enhancing, or restoring physical health and musculoskeletal function and may have a positive impact on any of the body systems ${ }^{8,9}$.

Prescription parameters of therapeutic exercise must include the type, mode, frequency, intensity, and duration of the exercise. The recommended dose of exercise under the prescription parameters should be sufficient to achieve the proposed therapeutic goals. Currently, the combination of these prescription parameters has generated multiple doses of exercise, whose effectiveness in this population is not yet known.

Literature has not reported a standard intervention yet or the application parameters that have been proven to be effective in enhancing these children's motor function. Considering the complexity of the motor function construct, which includes a significant number of outcomes, there is lack of accurate knowledge on which of them should be promoted or on the most appropriate therapeutic interventions to do so.

No systematic reviews assessing the effects of therapeutic exercise on children with DS during the first years of life have been identified in the reviewed literature. A significant number of systematic reviews on exercise in individuals with DS have been published. These reviews focused on the juvenile or adult stage of this population ${ }^{10,11}$, mainly assessing cardiovascular outcomes ${ }^{12,13}$. In childhood researches, there are also some systematic reviews on the effects of exercise. However, these publications have studied the effects of therapeutic aerobic exercise on children with intellectual disabilities ${ }^{14}$, including those with other conditions that are accompanied by an intellectual disability, such as cerebral palsy or autism ${ }^{15,16}$.

There are multiple interventions that can be carried out to improve the motor function of children with DS, which hinders clinical decision-making when the parameters that have been proven to be effective in the target population of this review are not clear. Likewise, the effective parameters of different types of exercises other than aerobic exercises in children with DS also remain unclear. Therefore, it is necessary to determine the effect of therapeutic exercise on the motor function of children with DS aged 0 to 3.

\section{Methods}

Methods We adhered to the Preferred Reporting Items for Systematic Reviews and MetaAnalyses (PRISMA) guidelines ${ }^{17 .}$

\section{Eligibility Criteria}

Type of study: A literature systematic review was carried out, including randomized controlled trials (RCTs) 
Type of participants: The participants of this study are children with DS aged 0 to 3 years, bearing in mind that, during this period, the interventions reported in the literature aim to enhance the occurrence of motor patterns in children with DS. After age 4, the therapeutic goal is mainly focused on enhancing or rehabilitating the motor functions ${ }^{18}$.

\section{Type of Interventions}

The study included all the therapeutic interventions that are duly applied and systematically planned physical exercises with specific prescription parameters in terms of intensity, frequency, and duration, among others, with the aim of promoting, improving, or maintaining the motor function of children with DS. Subsequently, long-duration interventions, in which the work of large muscle groups were promoted, were classified as aerobic exercise ${ }^{19}$. Therapeutic neuromuscular exercise was classified as the exercise aimed at improving the participants' balance or flexibility and as resistance training, short-duration exercises whose energy system was mainly anaerobic.

\section{Outcomes}

The reviewed literature showed publications on the key outcomes of being included in the RCTs assessing interventions in people with DS, however, these are cognitive and developmental outcomes ${ }^{20}$. Considering that a set of basic outcomes established within the motor function in children with DS were not identified in the reviewed literature, two groups of experts were consulted, one consisting of parents and/or caregivers of children with DS and another consisting of clinical experts.

The first group consisted of eight parents of children with DS from the Corporation of Down Syndrome of the city of Bogotá, Colombia. The group of experts comprised a general practitioner, with a Master's Degree in physiology and with expertise in physical exercise; a professional in psychology with experience in psychosocial support; a pediatric neurophysiotherapist with a Master's Degree in Physiotherapy; a physiotherapist with a Master's Degree in Epidemiology and with expertise in prescribing physical and therapeutic exercise; and three physiotherapists with extensive clinical experience treating people with DS.

The group of parents/caregivers rated the outcomes through a printed self-administered questionnaire prepared to that effect, and the group of experts rated the outcomes using a virtual questionnaire. Both groups prioritized outcomes on a 1-9 scale following the Grading of Recommendations Assessment, Development and Evaluation (GRADE) methodology ${ }^{21}$. The outcomes included in this review were those considered important but not critical (scores of 4 to 6 ) and critical for clinical decision-making (scores of 7 to 9$)^{21}$.

The outcomes defined for this age group were gait, balance, motor development, fine motor skills, and executive functions.

\section{Search and Identification of Studies}

The search strategy was designed based on the Population, Intervention, Comparison and Outcome (PICO) elements of the questions asked. These terms were adapted according to the languages of the different databases explored. A systematic search was conducted from January to December 2019 , on databases such as PubMed, PEDro, EMBASE, SciELO, Lilacs, and the Cochrane Library. Additionally, other sources of evidence were consulted to allow the identification and analysis of published and unpublished literature (gray literature) that would not have been detected through a systematic search. Manual searches were conducted in the documents found in the reference lists and in journals specialized in the subject. In addition, Epistemonikos was consulted for previous systematic reviews on this topic in order to review the primary studies included in them, and an evidence-based matrix was built based on this information. This process was developed during the months of January to December 2019.

The terms used included: Down syndrome, mongolism, trisomy, child, therapeutic exercise, exercise, aerobic, resistance training, physical therapy, physical, activity, therapeutic, resistance training, plyometric, stretching, anaerobic, bicycling, aquatic, rehabilitation, kinesiotherapy.

\section{Selection of Studies}

Study selection based on titles and abstracts was performed independently by two trained reviewers (EIRG and YSV). RCTs that assessed the effectiveness of therapeutic exercise and reported the effectiveness in the prioritized outcomes-gait, balance, motor development, fine motor skills, and executive functionswere selected.

Each assessor generated BibTeX files of the selected studies. Using a bibliographic manager, duplicates were regarded as studies with agreement between the assessors, and those that were not duplicated were reviewed individually by the two assessors and their eligibility was discussed and determined. The eligibility of those studies without a discussion-based consensus was decided by a third assessor.

Studies that did not include at least one of the outcomes or applied a combination of therapeutic exercise interventions and pharmacological interventions were excluded from the study.

\section{Extraction and Handling of Variables}

Data were extracted through pre-designed data collection formats. The data from the variables were collected for the comparison of the studies and the measurement of outcomes.

For the gait outcome, the data such as time-to-event or changes in the kinematic or kinetic parameters of this variable were extracted. For the balance outcome, the data on displacement of the center of mass or time maintaining postural balance were extracted. The independent variable comprised the type, 
mode, frequency, intensity, duration of the interventions, place of performance of the interventions (i.e., outpatient consultation or home) and the person in charge of applying the intervention (i.e., physiotherapist, other professional, family member, or caregiver).

Further data extracted from the population were age, sex, sample size for each group, and cognitive impairment.

\section{Assessment of Study Quality}

Two independent assessors evaluated the risk of bias for each study using the Cochrane Collaboration tool ${ }^{22}$. The risk was assessed as low risk of bias, high risk of bias, and unclear risk of bias taking into account six domains: random sequence generation (selection bias), allocation concealment (selection bias), participant and staff blinding (performance bias), blinding of outcome assessment (detection bias), incomplete outcome data, and selective outcome reporting (reporting bias). The rating of risk of bias was assessed using the RevMan 5.1 software ${ }^{23}$.

\section{Assessment of the Certainty of Evidence}

The assessment of the certainty of the evidence found was carried out using the GRADE approach ${ }^{21}$. The evidence found for each of the outcomes was rated considering the risk of bias, inconsistency, direct or indirect evidence and imprecision, the risk of selective outcome reporting, and the dose-response gradient. These outcomes were classified using a three-level ordinal scale that included very serious, serious, and not serious, except for the risk criteria for selective outcome reporting (not detected or strong suspicion), the size of the effect (no effect, large, or very large), the confounding factors (no effect, it would reduce the effect demonstrated, or suggest spurious effect), and the dose-response gradient (no or yes), in which nominal and ordinal scales with other levels were used $^{24}$.

\section{Synthesis of Data}

The selected body of evidence was assessed by prioritized outcomes. Each outcome described the population's features; the parameters of the interventions including the exercise mode applied, frequency, intensity, and duration of the interventions applied in the said studies; and the quantitative results achieved with their level of significance, shown in Table 1. The data were synthesized on a Microsoft Excel base, extracting data from the population's features, randomization methods, outcome measures, duration of follow-up, and assessment methods from each study. The meta-analysis considered direct comparisons between the experimental group who did the interventions (aerobic exercise and resistance exercise) and a control group who performed educational activities, recreational activities, or continuity with activities of daily living or interventions other than those of interest for this review.

Averages and standard deviations of the data available from the selected studies were extracted from the prioritized outcomes included in the studies. When the studies reported standard errors of the mean, the standard deviations were obtained by multiplying standard errors of the mean by the square root of the sample size. Standardized mean differences (SMDs) and $95 \%$ confidence intervals ( $95 \% \mathrm{Cl}$ ) were calculated to combine the results of the studies using different measures for the same concept or of studies presenting variability in its features.

Heterogeneity between trials was assessed using the chi-squared test, a significance value of $\mathrm{p}<0.05$ after due consideration of the value of $I 2^{25}$. In the presence of heterogeneity of the results determined by 12 greater than $70 \%$, the results were combined using the random effects model and the $95 \% \mathrm{Cl}$ was calculated. All of the above were carried out with the RevMan 5 software ${ }^{23}$.

\section{Results}

\section{Selection of Studies}

A total of 1384 studies were found as a result of the systematic literature search. 239 studies were found in other sources that included the bibliographic references of the studies found in the systematic search and in those provided by the group of experts, amounting to a total of 1623 identified studies. Of these studies, 88 duplicated ones were excluded and 1178 studies were excluded considering the review of the titles and abstracts. The two assessors reviewed a total of 357 full-text studies, of which 347 were excluded because they did not meet the eligibility criteria, mainly due to the type of design, and because they did not include any of the prioritized outcomes for the systematic review. The flow chart of the studies found and included in the body of evidence is presented in Figure 1.

Adapted from: Moher D, Liberati A, Tetzlaff J, Altman DG, The PRISMA Group (2009) Preferred Reporting Items for Systematic Reviews and Meta-Analyses: The PRISMA statement. PLoS Med 6(7): e1000097. doi:10.1371/journal.

Finally, six primary studies reported in eleven journals (thread) were included. Table 1 shows thread articles, primary studies, and reports linked to them ${ }^{26}$. 


\section{References of the studies included in this review:}

1. Looper J, Ulrich DA. Effect of treadmill training and supramalleolar orthosis use trial. Phys Ther. 2010 Mar 14;90(3):382-9027

2. Wu J, Looper J, Ulrich BD, Ulrich DA, Angulo-Barroso RM. Exploring effects of different treadmill interventions on walking onset and gait patterns in infants with Down syndrome. Developmental medicine and child neurology. 2007;49(11):839$45^{29}$. on motor skill development in infants with Down syndrome: a randomized clinical

\section{Reports linked to the studies included in this review:}

Looper J, Ulrich D. Does orthotic use affect upper extremity support during upright play in infants with down syndrome?. Pediatr Phys Ther.. 2011;23(1):70-7728

- Wu J, Looper J, Ulrich DA, Angulo-Barroso RM. Effects of various treadmill interventions on the development of joint kinematics in infants with Down syndrome. Physical therapy. 2010;90(9):1265$76^{30}$.

- Angulo-Barroso RM, Wu J, Ulrich DA. Long-term effect of different treadmill interventions on gait development in new walkers with Down syndrome. Gait \& posture. 2008;27(2):231-831.

- Ulrich DA, Lloyd MC, Tiernan CW, Looper JE, Angulo-Barroso RM. Effects of intensity of treadmill training on developmental outcomes and stepping in infants with Down syndrome: a randomized trial. Physical therapy. 2008;88(1):114-22 ${ }^{32}$.

3. Angulo-Barroso R, Burghardt AR, Lloyd M, Ulrich DA. Physical activity in infants with Down syndrome receiving a treadmill intervention. Infant behavior \& development. 2008;31(2):255-6914.

Lloyd M, Burghardt A, Ulrich DA, Angulo-Barroso R. Physical activity and walking onset in infants with Down syndrome. Adapt Phys Activ Q. 2010;27:1-16 33

4. Harris SR. Effects of neurodevelopmental therapy on motor performance of infants with Down's syndrome. Developmental medicine and child neurology. $1981 ; 23(4): 477-83^{34}$

5. Ulrich DA, Ulrich BD, Angulo-Kinzler RM, Yun J. Treadmill training of infants with Down syndrome: evidence-based developmental outcomes. Pediatrics. 2001;108(5):E84 ${ }^{35}$

6. Lowe L, McMillan AG, Yates C. Body Weight Support Treadmill Training for Children With Developmental Delay Who Are Ambulatory. Pediatric physical therapy : the official publication of the Section on Pediatrics of the American

Physical Therapy Association. 2015;27(4):386-9436.

Assessment of the Risk of Bias of the Studies Included

\section{Allocation (Selection Bias)}

Five studies showed unclear bias $27,29,34,35$ due to the fact that, although they mentioned the random allocation, the allocation methods for participants were not clear and whether the personnel in charge of maintaining the random allocation was masked was not established.

\section{Blinding}

Due to the nature of the interventions used, the assessment of the risk of bias took into account the masking of outcomes by the assessors in each study. In the studies included in this review, four studies showed a high risk of bias due to lack of masking ${ }^{27,29,35}$, since neither the staff nor the participants were masked. In the remaining studies ${ }^{14,34}$, the risk of bias was unclear (Figure 3 ).

\section{Outcomes with Incomplete Data}

Two of the studies included presented unclear risk of bias, as participants who did not adhere to the treatment protocol were excluded from the analysis ${ }^{14,34}$. Only one study presented a high risk of bias on this item since 5 out of 12 participants were missing in one of the comparison groups. Only the results from 7 participants were included in the analysis ${ }^{27}$.

\section{Selective Reporting}

One study was found to present high risk of bias ${ }^{27}$. The time of the independent walking event is considered an important outcome; nonetheless, the authors did not clearly report the time elapsed from the commencement of the study to the event of interest. Additionally, some data such as the analysis of video recordings collected during follow-ups were not reported.

\section{Other Potential Sources of Bias}

None of the studies included in the review clearly mentioned the training processes of the outcome assessors or the adjustment and calibration processes of the equipment used, which is the reason why all of the studies, with the exception of the Looper study, were considered to have unclear risks of bias ${ }^{27}$.

This information is summarized in Figures 2 and 3.

\section{Types of Therapeutic Exercise and Modes of Application in Physiotherapy Interventions in Children Aged 0 to 3 years}

In the literature included, only two types of therapeutic exercises were reported; the first one was classified as aerobic exercise as it included longer-duration interventions that promoted the work of large muscle groups ${ }^{19}$. Five out of six studies included in this review applied this type of exercise and all coincided in 
the way the exercise was applied, by using the treadmill14,27,29,35,36

The second type of exercise identified was neuromuscular, namely, the exercise that aims to improve the balance or flexibility of the participants. It mainly includes unstable surface activities ${ }^{19}$. The study by Harris SR was the only one including this type of exercise ${ }^{34}$.

Table 3 includes the characteristics of the interventions along with their respective application parameters.

\section{Frequency, Intensity, and Duration of the Interventions Used in This Population}

In those studies that applied aerobic therapeutic exercises using the treadmill (mode), the frequency ranged from three days ${ }^{36}$ to five days a week ${ }^{14,27,29,34,35}$.

The duration of each session varied between six $29,32,37$, eight ${ }^{27,35}$ and fifteen minutes ${ }^{36}$. The intensity was determined by the treadmill's speed, which ranged between $0.2 \mathrm{~m} / \mathrm{s}^{27,35}, 0.5 \mathrm{~m} / \mathrm{s}^{29,31,32}, 0.18$, and $0.22 \mathrm{~m} / \mathrm{s}^{37}$ and finally between 0.54 and $0.80 \mathrm{~m} / \mathrm{s}^{36}$.

With regard to the person who applied the intervention, this was carried out by professionals in the case of the studies by Lowe, L. ${ }^{36}$ and Angulo-Barroso, $\mathrm{R}^{37}$. In Looper, J. ${ }^{27}$, Wu, J. ${ }^{29}$, and Ulrich, D. A. ${ }^{35}$ studies, parents were trained to apply the intervention at home.

Harris SR et al. ${ }^{34}$ assessed an intervention that was different from the aerobic exercise. They applied neuromuscular exercise with a frequency of 3 times a week for 9 weeks, 40 minutes a day. This intervention was carried out by parents at home after receiving previous training.

\section{Outcomes Assessed in the Studies Included in the Review}

Of the outcomes proposed for assessment, no evidence was found for the executive function, balance, and fine motor outcomes in this population. Table 2 includes the features of the studies included in this review.

\section{Gait}

Five studies reviewed the effect of therapeutic exercise on the participants' gait. Angulo-Barroso ${ }^{14}$, Looper, J. ${ }^{27}$, Wu, J. ${ }^{29}$, and Ulrich, D. A. ${ }^{35}$ studies included the average time to achieve independent gait (Figure 4). Wu, $\mathrm{J}^{29}$ included 30 children with an average age of 10 months. These participants were included in the study when they could remain seated for 30 seconds. The outcome they assessed was the time to achieve independent gait and kinematic parameters of gait, as in the study published by Angulo-Barroso ${ }^{14}$. Finally, Lowe, L. ${ }^{36}$ included 24 participants in his study, with ages that ranged from 26 to 51 months, with the aim of assessing gait performance using the ten-minute gait test (Figure 5).

\section{Motor Development}

Five studies included motor development or motor function as outcome, assessed using scales, such as the Bayley Scales of Infant Development ${ }^{38}$, Gross Motor Function Measure (GMFM)(39), and Peabody Developmental Motor Scale(40). Looper, J. ${ }^{27}$ and Lowe, L. ${ }^{36}$ assessed the outcome using the GMFM scale, while Wu, J. ${ }^{29}$ and Ulrich, D. A. ${ }^{35}$ used the Bayley Scales of Infant Development for this purpose. Finally, Harris, S. R. ${ }^{34}$ used the Peabody Developmental Motor Scale (Figure 6).

\section{Assessment of the Certainty of the Evidence Identified}

The certainty of the evidence for the gait and motor development outcomes was moderate and high, respectively (Table 3). The certainty of the evidence was considered moderate mainly due to the imprecision of the results obtained in the primary studies and the indirect evidence from one of the studies ${ }^{36}$. 
Table 2. Assessing the certainty of the evidence presented for each outcome.

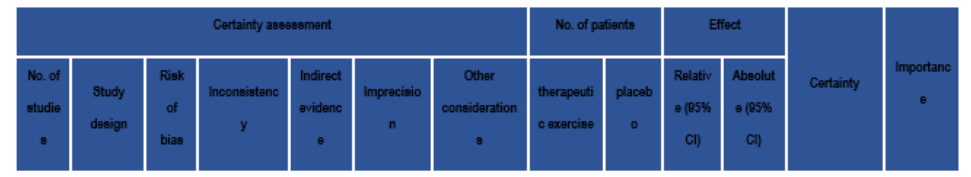

Independent gait three staps without aseistance. Traadmill-type aerobic Theraputic exercise va. control (assessed with: daye-to-event)

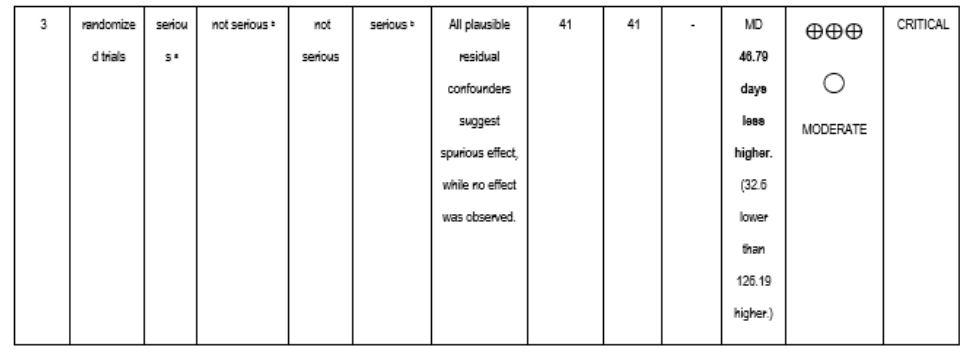

Motor development (mental dimension) intervention: neuromuscular axarcise ve control (regular interventions) (ase日esed with: Gross motor function maasure)

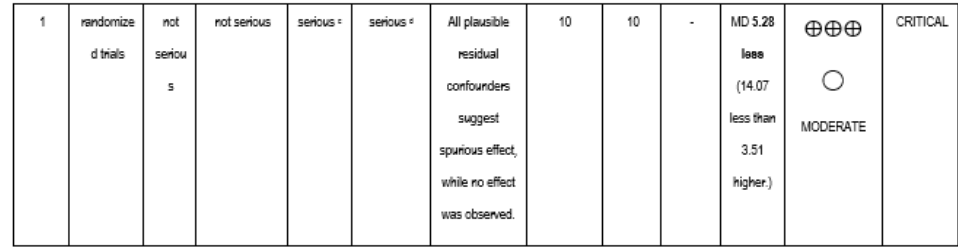

Motor development (motor dimension): intervention: neuromuscular exercies vs control (regular intarventions) (assessed with: Groses motor function mesaure)
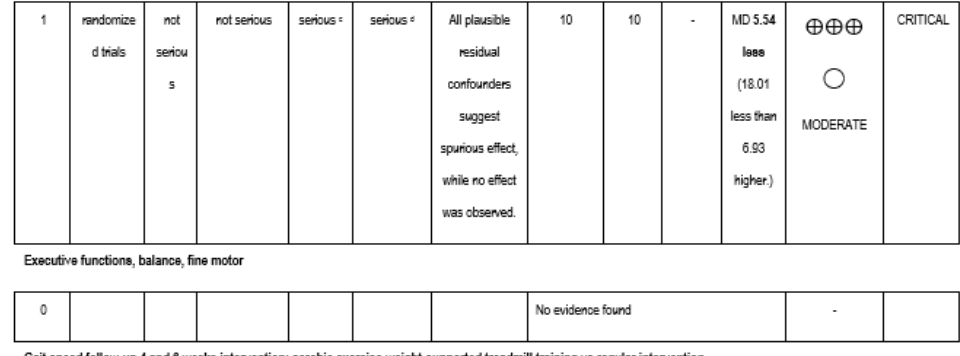

Gait spead follow-up 4 and 6 weaks intarvention: arrobic exercis-weight-supportad traadmill training va regular intervention
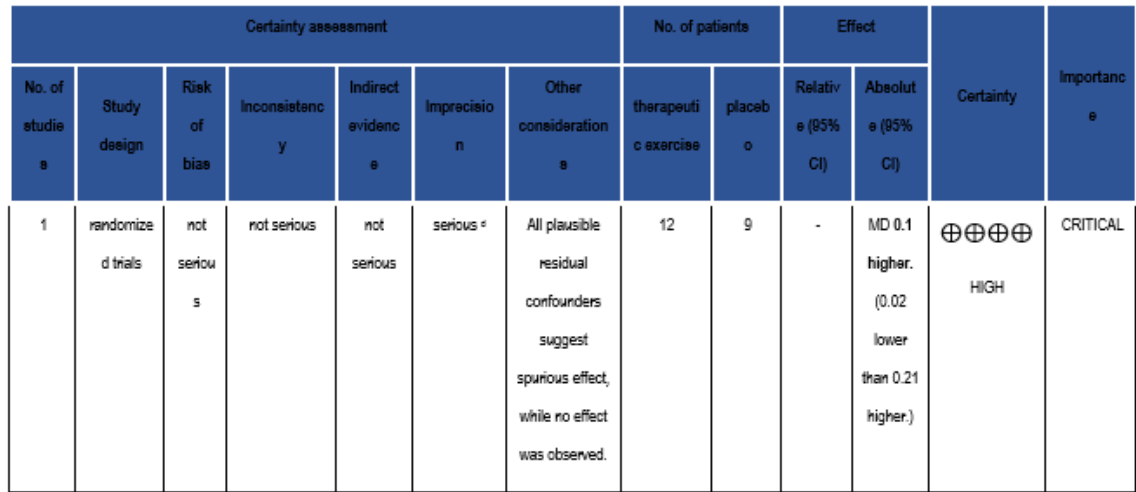

Motor development follow-up 4 and 6 wøeks intervention: aerobic exercise-weight-supported traadmill training vs regular intervention (aseessed with: GMFMI)

\begin{tabular}{|c|c|c|c|c|c|c|c|c|c|c|c|c|}
\hline 1 & $\begin{array}{c}\text { randomize } \\
d \text { trials }\end{array}$ & $\begin{array}{c}\text { not } \\
\text { seriou } \\
5\end{array}$ & rot serious & $\begin{array}{c}\text { not } \\
\text { serious }\end{array}$ & serious: & $\begin{array}{l}\text { All plausble } \\
\text { residual } \\
\text { confourders } \\
\text { suggest } \\
\text { spurious effect, } \\
\text { while no effect } \\
\text { was observed. }\end{array}$ & 12 & 9 & . & $\begin{array}{c}\text { MD } 2.07 \\
\text { higher. } \\
(0.28 \\
\text { higher } \\
\text { than } 3.86 \\
\text { higher.) }\end{array}$ & $\begin{array}{c}\oplus \oplus \oplus \oplus \\
\text { HIGH }\end{array}$ & CRITICAL \\
\hline
\end{tabular}

$\mathrm{MD}$ : mean difference

Table 3. Characteristics of the studies included regarding therapeutic exercise in children with DS aged 0 to 3 years. 


\begin{tabular}{|c|c|c|c|c|c|c|}
\hline Reference & Design & Participants & Interventions & $\begin{array}{c}\text { Outcomes, } \\
\text { measurement } \\
\text { tools }\end{array}$ & $\begin{array}{l}\text { Application } \\
\text { parameters }\end{array}$ & Results \\
\hline Looper, J. ${ }^{27}$ & ECA & $\begin{array}{l}\text { DI: NR } \\
\text { N: } 17 \\
\text { H:NR } \\
\text { M:NR } \\
\text { Age } 21.4 \pm 4 \text { months }\end{array}$ & $\begin{array}{l}\text { Group 1: Treadmill and orthosis } \\
\text { (eight hours a week), regular } \\
\text { physiotherapy } \\
\text { Group 2: treadmill, regular } \\
\text { physiotherapy. }\end{array}$ & $\begin{array}{l}\text { * Independent gait: } \\
\text { days to the event } \\
\text { (gait: } 3 \text { independent } \\
\text { steps) } \\
\text { * Motor function: } \\
\text { GMFM }\end{array}$ & $\begin{array}{l}\text { Type: aerobic } \\
\text { Mode: Treadmill } \\
\text { Frequency: } 5 \text { days a week } \\
\text { Duration: } 8 \text { minutes a day } \\
\text { Intensity: Treadmill speed } \\
0.2 \text { m/s } \\
\text { Intervention applied } \\
\text { by: parents at home. }\end{array}$ & $\begin{array}{l}\text { Average time to event: } \\
\text { independent gait } \\
\text { (three consecutive } \\
\text { steps without } \\
\text { assistance) } \\
\text { Group 1: } 206 \pm 109 \\
\text { days from the } \\
\text { beginning of the } \\
\text { intervention until the } \\
\text { event. } \\
\text { Group 2: days to the } \\
\text { event 268 } \pm 88 \\
\text { Motor function } \\
\text { Higher scores in the } \\
\text { group without orthosis } \\
\text { at one-month follow- } \\
\text { up. } \\
\text { p<0.01 } \\
\text { Group 1: GMFM pos } \\
\text { 195.65 } \pm 8.12 . \\
\text { Group 2: GMFM pos } \\
183.78 \pm 7.22\end{array}$ \\
\hline Wu, J. ${ }^{29}$ & ECA & $\begin{array}{l}\text { DI: NR } \\
\text { N:30 } \\
\text { H:18 } \\
\text { M:12 } \\
\text { Age } 10.4 \pm 2.14 \text { months }\end{array}$ & $\begin{array}{l}\text { Group 1: Treadmill at generally } \\
\text { low intensity. } \\
\text { Frequency: } 5 \text { days a week } \\
\text { Duration: } 6 \text { minutes a day } \\
\text { Intensity: Treadmill speed } 0.18 \\
\text { m/s } \\
\text { Group 2: Treadmill at } \\
\text { individualized high intensity } \\
\text { Frequency: } 5 \text { days a week } \\
\text { Duration: } 8 \text { minutes a day } \\
\text { Intensity: Treadmill speed } 0.5 \mathrm{~m} / \mathrm{s} .\end{array}$ & $\begin{array}{l}\text { Independent gait: } \\
\text { Step length, stride } \\
\text { length, speed } \\
\text { Motor development: } \\
\text { Bayley Scales for } \\
\text { Infant Development }\end{array}$ & $\begin{array}{l}\text { Type: aerobic } \\
\text { Mode: Treadmill } \\
\text { Progression: high intensity } \\
\text { group: Treadmill duration } \\
\text { and speed with ankle } \\
\text { weights. } \\
\text { Intervention applied } \\
\text { by: parents at home }\end{array}$ & $\begin{array}{l}\text { Differences favoring } \\
\text { group 1, both in } \\
\text { months to the event } \\
\text { and in gait parameters } \\
\mathrm{p}<0.05 \\
\text { Group 1: } 19.2 \text { months } \\
\text { from the beginning of } \\
\text { the intervention until } \\
\text { event. } \\
\text { Group 2: } 21.4 \text { months } \\
\text { to event }\end{array}$ \\
\hline $\begin{array}{l}\text { Angulo- } \\
\text { Barroso, }\end{array}$ & ECA & DI: NR & $\begin{array}{l}\text { Group 1: Treadmill at generally } \\
\text { low intensity. }\end{array}$ & $\begin{array}{l}\text { * Independent gait: } \\
\text { days to the event }\end{array}$ & Type: aerobic & $\begin{array}{l}\text { Group } 1 \text { significant } \\
\text { differences in time to }\end{array}$ \\
\hline
\end{tabular}




\begin{tabular}{|c|c|c|c|c|c|c|}
\hline R. ${ }^{14}$ & & $\begin{array}{l}\mathrm{N}: 30 \\
\mathrm{H}: 18 \\
\mathrm{M}: 12 \\
\text { Age } 10.4 \pm 2.2 \text { months }\end{array}$ & $\begin{array}{l}\text { Group 2: Treadmill at } \\
\text { individualized high intensity }\end{array}$ & $\begin{array}{l}\text { (gait: } 3 \text { independent } \\
\text { steps) } \\
\text { *Parameters }\end{array}$ & $\begin{array}{l}\text { Mode: treadmill } \\
\text { Frequency: } 5 \text { days a week } \\
\text { Duration: } 6 \text { minutes a day } \\
\text { Intensity: speed } 0.18 \mathrm{~m} / \mathrm{s}- \\
0.22 \mathrm{~m} / \mathrm{s} \\
\text { Intervention applied } \\
\text { by: health professional }\end{array}$ & $\begin{array}{l}\text { event and in the } \\
\text { development of the } \\
\text { kinematic parameters } \\
\text { of gait compared to } \\
\text { group } 2 \text {. } \mathrm{P}<0.05 \text {. }\end{array}$ \\
\hline $\begin{array}{l}\text { Harris, S. } \\
\text { R. }^{34}\end{array}$ & ECA & $\begin{array}{l}\text { DI: NR } \\
\text { N:20 } \\
\text { H:9 } \\
\text { M:11 } \\
\text { Age } 10.91 \pm 7.64 \text { months }\end{array}$ & $\begin{array}{l}\text { Experimental group: } \\
\text { neurodevelopmental therapy } \\
\text { Control group: activities of daily } \\
\text { living }\end{array}$ & $\begin{array}{l}\text { * Motor } \\
\text { development } \\
\text { Bayley and Peabody } \\
\text { Scales (fine and } \\
\text { gross motor skills) }\end{array}$ & $\begin{array}{l}\text { Type: neuromuscular } \\
\text { Mode: Specific } \\
\text { neurodevelopmental } \\
\text { techniques that included } \\
\text { joint approaches and } \\
\text { resisted movements for } \\
\text { postural tone, protective } \\
\text { reactions and balance in } \\
\text { supine and quadruped, } \\
\text { rolling and creeping. } \\
\text { Frequency: } 3 \text { times a week } \\
\text { for } 9 \text { weeks. } \\
\text { Intervention applied by: } \\
\text { parents at home } \\
\text { Intensity: NR }\end{array}$ & $\begin{array}{l}\text { There were no } \\
\text { significant differences } \\
\text { between the groups, } \\
\text { however, the } \\
\text { experimental group } \\
\text { showed significant } \\
\text { differences between } \\
\text { the initial and final } \\
\text { measurement. }\end{array}$ \\
\hline $\begin{array}{l}\text { Ulrich, D. } \\
\text { A.35 }\end{array}$ & ECA & $\begin{array}{l}\text { DI: NR } \\
\text { N:30 } \\
\text { H:NR } \\
\text { M:NR } \\
\text { Age } 9.2 \pm 0.5 \text { months }\end{array}$ & $\begin{array}{l}\text { Group 1: Treadmill and } \\
\text { comprehensive physiotherapy } \\
\text { Group 2: comprehensive } \\
\text { physiotherapy }\end{array}$ & $\begin{array}{l}\text { Independent gait: } \\
\text { time to event } \\
\text { Motor } \\
\text { development: Bayley } \\
\text { Scales for Infant } \\
\text { Development }\end{array}$ & $\begin{array}{l}\text { Type: aerobic } \\
\text { Mode: Treadmill } \\
\text { Frequency: } 5 \text { days a week } \\
\text { Duration: } 8 \text { minutes a day } \\
\text { Intensity: Treadmill speed } \\
0.2 \text { m/s } \\
\text { Intervention applied } \\
\text { by: parents at home } \\
\text { Traditional } \\
\text { physiotherapy: health } \\
\text { professional }\end{array}$ & $\begin{array}{l}\text { Independent gait } \\
\text { Group 1: } 73.8 \text { days } \\
\text { from the beginning of } \\
\text { the intervention until } \\
\text { the event. } \\
\text { Group 2: days to event } \\
101 \text { days. }\end{array}$ \\
\hline Lowe $\mathrm{L}^{36}$ & ECA & DI: NR & $\begin{array}{l}\text { Control group: PT sessions } \\
\text { consisting of therapeutic activities }\end{array}$ & $\begin{array}{l}\text { Gait: } 10 \text { minutes } \\
\text { gait test }\end{array}$ & Type: aerobic & $\begin{array}{l}\text { There were no } \\
\text { significant differences }\end{array}$ \\
\hline
\end{tabular}




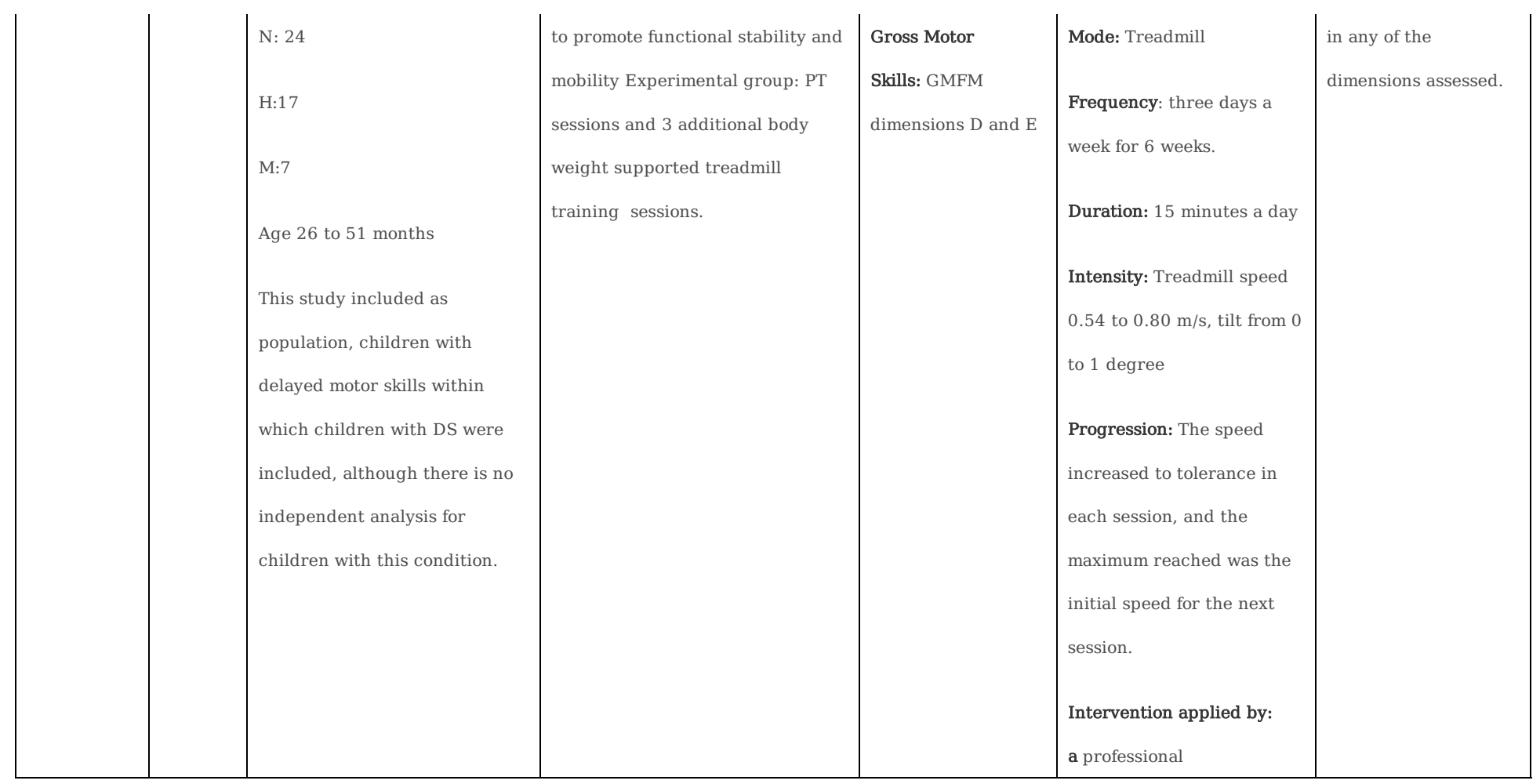

GMFM: Gross Motor Function Measure

\section{Discussion}

There are a significant number of publications on therapeutic interventions in physical rehabilitation in children with DS. These include some systematic reviews that have sought to describe aerobic exercise in children with psychomotor retardation ${ }^{15,16}$, within which children with DS are classified as a subgroup. Other publications have focused on physiotherapy interventions in the population with DS throughout the life cycle ${ }^{18}$; however, this is the first systematic review identified in the literature reviewed aimed at assessing the effectiveness of interventions framed within therapeutic exercise (aerobic, resistance, neuromuscular, or neuromotor ${ }^{19}$ in children aged 0 to 3 years, the stage at which therapeutic interventions are focused on promoting the occurrence of adequate motor patterns ${ }^{5}$.

Bearing in mind that motor function is a construct that encompasses multiple outcomes and that therapeutic exercise interventions under prescription parameters may favor one outcome over another, this review determined outcomes based on the preferences of parents and caregivers and professional experts treating this population. It intended to identify responses in the literature that could meet their interests and, in the case of the experts, to give response to their concerns when making clinical decisions about which type of intervention to use and effective prescription parameters to achieve successful outcomes of interest that will ultimately become the therapeutic goals of clinical interventions.

The evidence identified was scarce in terms of interventions and selected outcomes and their quality. Although they corresponded to randomized clinical experiments, they presented high risk and unclear risk of bias in aspects that jeopardize the internal validity of the study and therefore the certainty when measuring the effect, for example, in the random allocation ${ }^{27,29,34,35}$, in the concealment $27,29,29,35$, in the selective data reporting ${ }^{27}$, and in the follow-up losses, which could lead to selection bias ${ }^{14,34}$. Furthermore, the sample sizes were small, which may explain the width of the confidence intervals and the insignificant differences reported by some studies ${ }^{34,36}$.

The evidence identified corresponds to the same group of authors who, in addition, have carried out a number of thread publications as secondary analyses of the studies carried out, published more than once in different journals (Table 1), which is the reason why these types of publications needed to be independently identified, reported, and not included in the quantitative analyses. New evidence is required, with larger sample sizes and better quality to validate the reported results.

The literature reviewed showed interventions that can be classified into two main types of exercise: aerobic and neuromuscular. Regarding the outcomes outlined in the review, evidence could only be found for the gait and motor development outcomes. For the gait outcome, there is evidence supporting the use of aerobic therapeutic treadmill exercise. This type and mode of exercise was used in five of the six studies identified in this review. After training, parents were in charge of administering the intervention, which consisted of providing stimulation of the gait pattern in children who had not developed the pattern ${ }^{27,29,32,37}$, following previously established parameters. Primary studies showed statistically significant differences in the time-to-the independent gait-event when applying the intervention with a frequency of 5 days, a duration of 6 to 8 minutes, and an intensity of between 0.2 and $0.5 \mathrm{~m} / \mathrm{s}$.

These findings validate the use of the treadmill as an application mode that can be used in rehabilitation centers for children with DS, as a strategy included in the set of interventions carried out in physiotherapy to promote gait patterns. In the identified evidence, parents applied the intervention at home, which could

Page 10/16 
suggest the use of this intervention as an adjunct to the interventions carried out in rehabilitation centers. However, before recommending its use at home, budget impact and cost-effectiveness analyses would be required to determine whether the benefits achieved would justify the cost of including these interventions ${ }^{41}$.

Only one study applied the intervention with the aim of enhancing the gait patterns of children aged between 26 and 51 months. In this case, no significant differences were found that resulted from the intervention, which may be explained by the frequency and duration parameters, as the frequency was three days a week and 15 minutes a day. Another explanation for these results could be the small size of the sample, which could result in a type 2 error. Another reason could be the selection bias since there was a difference in the number of girls and boys included and because the population included children with DS and cerebral palsy, among others, and the authors did not carry out a subgroup analysis ${ }^{42}$

The other outcome reported in literature was motor development. This was the purpose of studies that included aerobic exercise using a treadmill ${ }^{14,27,29,35,36}$ and neuromuscular exercise ${ }^{34}$. Significant differences were reported when using the parameters.

Only one study reported the application of this type of exercise to improve the motor development in children with DS. The authors did not report significant differences in the outcome measured using the Bayley and Peabody Scales. There is evidence of the effectiveness of this type of exercise in improving the balance in older children with DS ${ }^{43,44}$; however, this outcome was not measured in the aforementioned study.

There are innumerable interventions regularly used in physical rehabilitation in institutions treating children with DS that include rehabilitation approaches such as Bobath and Vojta, among others. Hydrotherapy and hippotherapy interventions are also offered in the management of these children. Surprisingly, there is no good-quality evidence to support the use of these modalities ${ }^{45}$. Interventions such as hydrotherapy or aquatic therapy, which has been proven to be effective in improving clinical variables in other populations ${ }^{46,47}$, did not provide evidence that could support their use in the subject population of this review.

Future studies are expected to assess the effects of interventions that are currently used with robust research designs. New evidence is required that increases certainty regarding the measurement of the effects achieved by the studies herein reported. Additionally, it is important to include budget impact and costeffectiveness analyses for the interventions mentioned herein.

\section{Limitations of the Study}

One limitation of the study is the low number of studies that fulfilled the eligibility criteria in terms of outcomes. Therefore, future studies may yield different results for the outcomes posed in this review.

The small number of studies was also reported by the authors themselves, which does not allow for a comparative analysis between prescription parameters and even the mode of application of the exercise.

No studies in children aged less than nine months were identified.

\section{Conclusions}

There is moderate to high evidence to support that therapeutic exercise promotes the occurrence of motor patterns such as gait patterns and improves the motor skills in children with DS aged 0 to 3 years.

More better-quality evidence is required to validate the mode of application and other prescription parameters discussed here.

Future research is required to support the use of effective prescription parameters of the many interventions currently employed in care settings within this population.

\section{Abbreviations}

DS: Down syndrome; GMFM: Gross Motor Function Measure; GRADE: Grading of Recommendations Assessment, Development and Evaluation; PICO: Population, Intervention, Comparison and Outcome; TD: Typically developing Lista de abreviaturas después de conclusiones

\section{Declarations}

\section{Author contributions}

ERG, ABL and MTN designed the study, ERG and YSV searched and selected the evidence, extracted, and synthesized data. FVP and CA advised the methodology and collaborated in the data analysis. All authors prepared and reviewed the manuscript.

\section{Funding}

This is a non-funded study

\section{Competing interests}

The authors declare that they have no competing interests. 


\section{References}

1. Chen C-CJJ RD. Treadmill walking effects on grip strength in young men with Down syndrome. Res Dev Disabil. 2014;288-93.

2. Lin H-C, Wuang Y-P. Strength and agility training in adolescents with Down syndrome: a randomized controlled trial. Res Dev Disabil. 2012 Dec;33(6):2236-44.

3. cano de la cuerda R, Molero-sanchez A, Carratalá-tejada M, Alguacil IM, Molina-Rueda F et al. Theories and control models and motor learning: Clinical applications in neurorehabilitation - 1-s2.0-S2173580814001424.pdf. 2015. 30(1):32-41.

4. ED390210.pdf [Internet]. [cited 2016 Nov 6]. Available from: http://files.eric.ed.gov/fulltext/ED390210.pdf

5. Ferreira-vasques at, lamônica dac. Motor, linguistic, personal and social aspects of children with Down syndrome. J Appl Oral Sci. 2015;23(4):424-30.

6. Sara M. Bauer, Emily A. Jones. A Behavior Analytic Approach to Exploratory Motor Behavior How Can Caregivers Teach EM Behavior to Infants With Down Syndrome? 2014. 27(2):162-73.

7. Dolva A-S, Coster W, Lilja M. Functional performance in children with Down syndrome. Am J Occup Ther Off Publ Am Occup Ther Assoc. 2004 Dec;58(6):621-9.

8. American College of Sports Medicine, Thompson WR, Gordon NF, Pescatello LS. ACSM's guidelines for exercise testing and prescription. Philadelphia: Wolters Kluwer/Lippincott Williams \& Wilkins; 2010.

9. Larun L, Brurberg GK, OdgaardJensen J, Price JR. Exercise therapy for chronic fatigue syndrome [Systematic Review]. Cochrane Database Syst Rev 2016. 2016;

10. Johnson CC. The benefits of physical activity for youth with developmental disabilities: a systematic review. Am J Health Promot AJHP. 2009 Feb;23(3):157-67.

11. Andriolo RB, El Dib RP, Ramos L, Atallah AN, da Silva EM. Aerobic exercise training programmes for improving physical and psychosocial health in adults with Down syndrome. Cochrane Database Syst Rev Online. 2010 Jun 16;5(5):CD005176.

12. Dodd K, Shields N. A systematic review of the outcomes of cardiovascular exercise programs for people with Down syndrome. Database Abstr Rev Eff DARE [Internet]. 2007 Sep 30; Available from: http://www.epistemonikos.org/documents/78ec19fda9cb7c685616830f7ffd28a7256040b5

13. Flore P, Bricout V-A, van Biesen D, Guinot M, Laporte F, Pepin J-L, et al. Oxidative stress and metabolism at rest and during exercise in persons with Down syndrome. Eur J Cardiovasc Prev Rehabil Off J Eur Soc Cardiol Work Groups Epidemiol Prev Card Rehabil Exerc Physiol. 2008 Feb;15(1):35-42.

14. Angulo-Barroso R, Burghardt AR, Lloyd M, Ulrich DA. Physical activity in infants with Down syndrome receiving a treadmill intervention. Infant Behav Dev. 2008 Apr;31(2):255-69.

15. Valentin-Gudiol M, Bagur-Calafat C, Girabent-Farres M, Hadders-Algra M, Mattern-Baxter K, Angulo-Barroso R. Treadmill interventions with partial body weight support in children under six years of age at risk of neuromotor delay: a report of a Cochrane systematic review and meta-analysis. Eur $\mathrm{J}$ Phys Rehabil Med. 2013 Feb;49(1):67-91.

16. Valentin-Gudiol M., Mattern-Baxter K., Girabent-Farrés M., Bagur-Calafat C., Hadders-Algra M., Angulo-Barroso R.M. Treadmill interventions with partial body weight support in children under six years of age at risk of neuromotor delay. Cochrane Database Syst Rev Online. 2011;12((Valentin-Gudiol M.) Physical Therapy, Universitat Internacional de Catalunya, C/Josep Trueta s/n, Sant Cugat del Vallès, Barcelona, Spain, 08195 .):CD009242.

17. Moher D, Liberati A, Tetzlaff J, G. Altman D. Preferred Reporting Items for Systematic Reviews and Meta-Analyses: The PRISMA Statement. PLoS Med [Internet]. [cited 2021 May 11];6(7). Available from: https://journals.plos.org/plosmedicine/article?id=10.1371/journal.pmed.1000097

18. Ruiz-González L, Lucena-Antón D, Salazar A, Martín-Valero R, Moral-Munoz JA. Physical therapy in Down syndrome: systematic review and meta-analysis. J Intellect Disabil Res JIDR. 2019;63(8):1041-67.

19. EJERCICIO TERAPÉUTICO. Fundamentos y técnicas - Carolyn Kisner, Lynn A. Colby - Google Books [Internet]. [cited 2020 Feb 1]. Available from: https://books.google.com.co/books? id=4KDLRvjzC_oC\&pg=PA15\&dq=ejercicio+terape\%C3\%BAtico\&hl=en\&sa=X\&ved=0ahUKEwjOq_qs27HnAhUxuVkKHSO7CyIQ6AEIKDAA\#v=onepage\&q=ej

20. Esbensen AJ, Hooper SR, Fidler D, Hartley S, Edgin J, d'Ardhuy XL, et al. Outcome Measures for Clinical Trials in Down Syndrome. Am J Intellect Dev Disabil. 2017 May;122(3):247-81.

21. Sanabria AJ, Rigau D, Rotaeche R, Selva A, Marzo-Castillejo M, Alonso-Coello P. Sistema GRADE: metodología para la realización de recomendaciones para la práctica clínica. Aten Primaria. 2015 Enero;47(1):48-55.

22. Cochrane Handbook for Systematic Reviews of Interventions [Internet]. [cited 2017 May 9]. Available from: http://handbook.cochrane.org/

23. RevMan 5 download | Cochrane Training [Internet]. [cited 2020 Mar 27]. Available from: https://training.cochrane.org/online-learning/core-softwarecochrane-reviews/revman/revman-5-download

24. GRADE handbook [Internet]. [cited 2020 Mar 27]. Available from: https://gdt.gradepro.org/app/handbook/handbook.html

25. Higgins JPT, Thompson SG. Quantifying heterogeneity in a meta-analysis. Stat Med. 2002 Jun 15;21(11):1539-58.

26. Epistemonikos: Database of the best Evidence-Based Health Care [Internet]. [cited 2020 Mar 28]. Available from:

https://www.epistemonikos.org/en/documents/3e07214980ff84a2c03884055427aae6642e5945/matrix?current=5e050f0c6ec0d638046c4982

27. Looper J, Ulrich DA. Effect of treadmill training and supramalleolar orthosis use on motor skill development in infants with Down syndrome: a randomized clinical trial. Phys Ther. 2010 Mar 14;90(3):382-90.

28. Looper J, Ulrich D. Does orthotic use affect upper extremity support during upright play in infants with down syndrome? Pediatr Phys Ther Off Publ Sect Pediatr Am Phys Ther Assoc. 2011;23(1):70-7. 
29. Wu J, Looper J, Ulrich BD, Ulrich DA, Angulo-Barroso RM. Exploring effects of different treadmill interventions on walking onset and gait patterns in infants with Down syndrome. Dev Med Child Neurol. 2007 Nov;49(11):839-45.

30. Wu J., Looper J., Ulrich D.A., Angulo-Barroso R.M. Effects of various treadmill interventions on the development of joint kinematics in infants with Down syndrome. Phys Ther. 2010;90(9):1265-76.

31. Angulo-Barroso RM, Wu J, Ulrich DA. Long-term effect of different treadmill interventions on gait development in new walkers with Down syndrome. Gait Posture. 2008 Feb 17;27(2):231-8.

32. Ulrich DA LM Tiernan CW, Looper JE, Angulo-Barroso RM. Effects of intensity of treadmill training on developmental outcomes and stepping in infants with Down syndrome: a randomized trial. Physical therapy. 2008.

33. Lloyd M, Burghardt A, Ulrich DA, Angulo-Barroso R. Physical activity and walking onset in infants with Down syndrome. Adapt Phys Act Q APAQ. 2010 Jan;27(1):1-16.

34. Harris SR. Effects of neurodevelopmental therapy on motor performance of infants with Down's syndrome. Dev Med Child Neurol. 1981 Aug;23(4):47783.

35. Ulrich DA UB Angulo-Kinzler RM, Yun J. Treadmill training of infants with Down syndrome: evidence-based developmental outcomes. Pediatrics. 2001.

36. Lowe L, McMillan AG, Yates C. Body Weight Support Treadmill Training for Children With Developmental Delay Who Are Ambulatory. Pediatr Phys Ther Off Publ Sect Pediatr Am Phys Ther Assoc. 2015;27(4):386-94.

37. Angulo-Barroso R., Burghardt A.R., Lloyd M., Ulrich D.A. Physical activity in infants with Down syndrome receiving a treadmill intervention. Infant Behav Dev. 2008;31(2):255-69.

38. Bayley-III Clinical Use and Interpretation - Google Books [Internet]. [cited 2020 Feb 1]. Available from: https://books.google.com.co/books? id=IsEIVHFTXf0C\&printsec=frontcover\&dq=bayley+scale\&hl=en\&sa=X\&ved=0ahUKEwiThbLT5bHnAhXFt1 kKHUrkDXcQ6AEIKDAA\#v=onepage\&q=bayley\%

39. Alesi M., Battaglia G., Pepi A., Bianco A., Palma A. Gross motor proficiency and intellectual functioning A comparison among children with down syndrome, children with borderline intellectual functioning, and typically developing children. Med U S [Internet]. 2018;97(41). Available from: http://www.embase.com/search/results? subaction=viewrecord\&from=export\&id=L627462095

40. Chien C.-W., Bond T.G. Measurement properties of fine motor scale of peabody developmental motor scales-second edition: A rasch analysis. Am J Phys Med Rehabil. 2009;88(5):376-86.

41. Orlewska E, Gulácsi L. Budget-Impact Analyses. PharmacoEconomics. 2009 Oct 1;27(10):807-27.

42. Introducción de Errores en la Medición. ITM; 2007. 42 p.

43. Boswell B. Comparison of two methods of improving dynamic balance of mentally retarded children. Percept Mot Skills. 1991 Dec;73(3 Pt 1):759-64.

44. Sugimoto D, Bowen SL, Meehan WP, Stracciolini A. Effects of Neuromuscular Training on Children and Young Adults with Down Syndrome: Systematic Review and Meta-Analysis. Res Dev Disabil. 2016 Apr 25;55:197-206.

45. Kavlak E., Unal A., Tekin F., Al Sakkaf A., Kavlak H.A. Comparison of efficiency of early term physiotherapy approach in babies with Down syndrome: Bobath versus Vojta. Dev Med Child Neurol. 2018;60((Kavlak E.; Unal A.; Tekin F.; Al Sakkaf A.; Kavlak H.A.) Pamukkale University, Denizili, Turkey):43-4.

46. Roostaei M, Baharlouei H, Azadi H, Fragala-Pinkham MA. Effects of Aquatic Intervention on Gross Motor Skills in Children with Cerebral Palsy: A Systematic Review. Phys Occup Ther Pediatr. 2017 Oct 20;37(5):496-515.

47. Marinho-Buzelli AR, Bonnyman AM, Verrier MC. The effects of aquatic therapy on mobility of individuals with neurological diseases: a systematic review. Clin Rehabil. 2015 Aug;29(8):741-51.

\section{Figures}




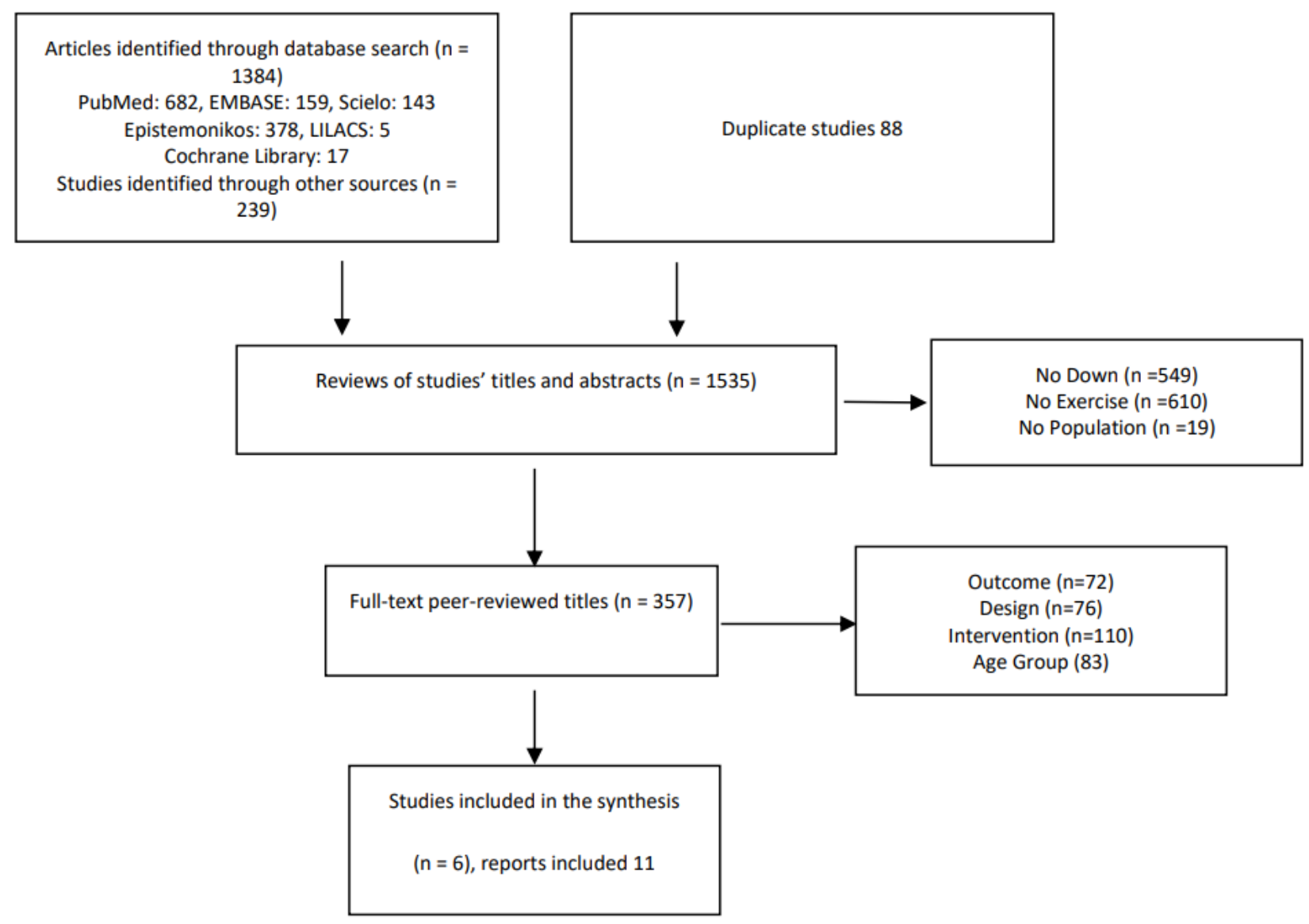

\section{Figure 1}

Flow chart of the studies included in the body of evidence on the type of therapeutic exercises effective in promoting, improving, or maintaining the motor function of children with DS aged 0 to 3 years. 


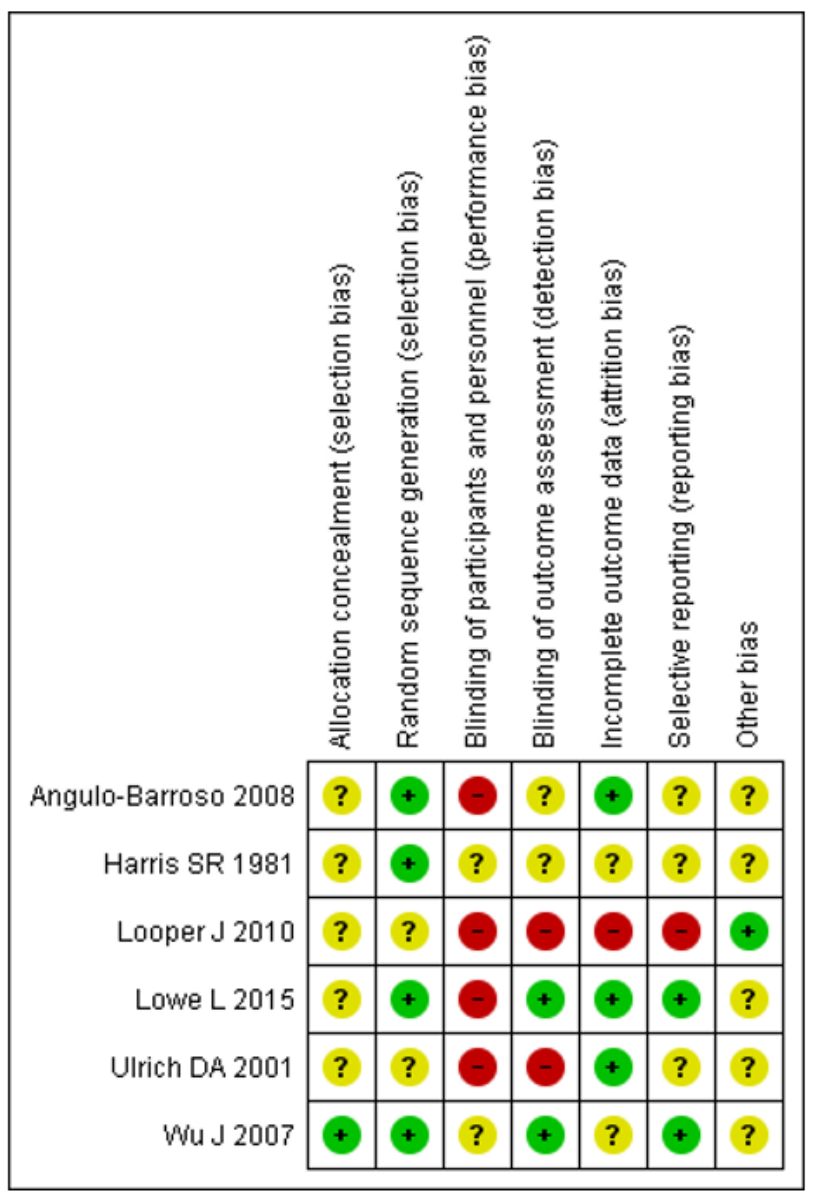

Figure 2

Risk of bias summary: review authors' judgments on each risk of bias item for each included study.

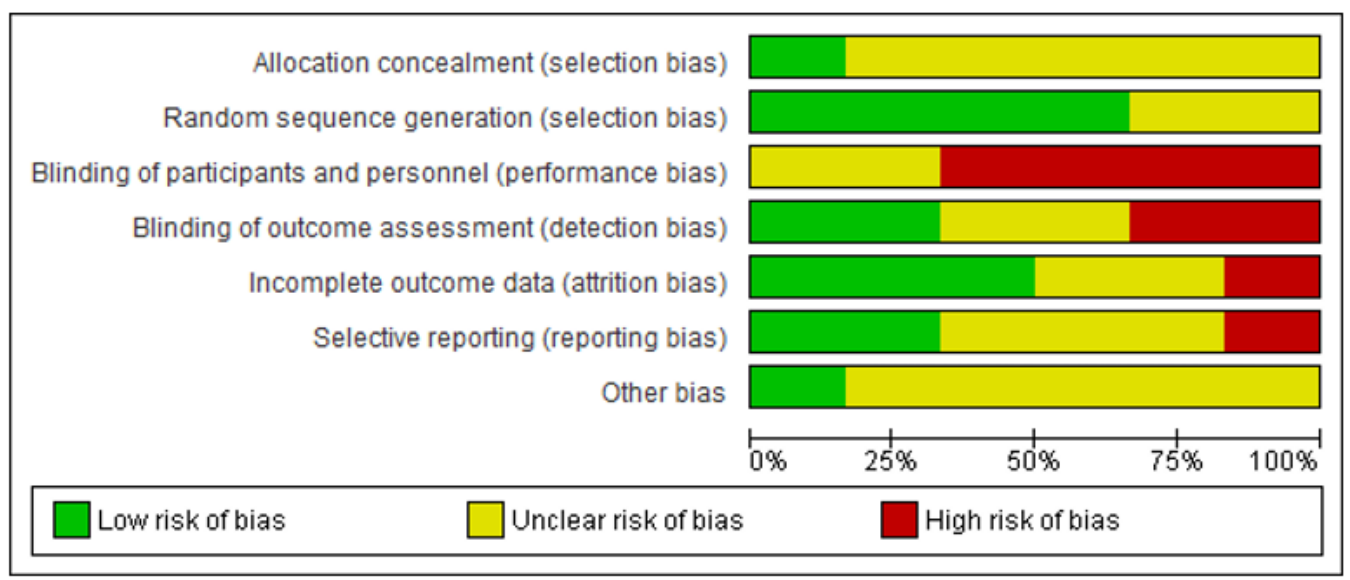

Figure 3

Risk of bias graph: review authors' judgments on each risk of bias item presented as percentages across all included studies. 


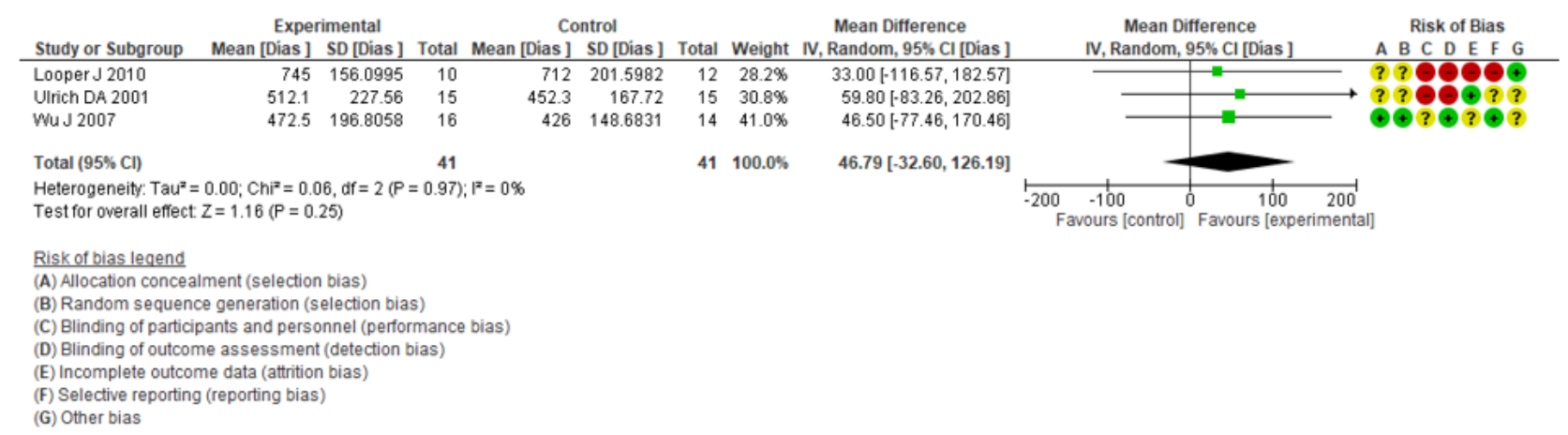

\section{Figure 4}

Aerobic exercise (treadmill) versus control (activities of daily living) outcome: independent gait, time(days)-to-event.

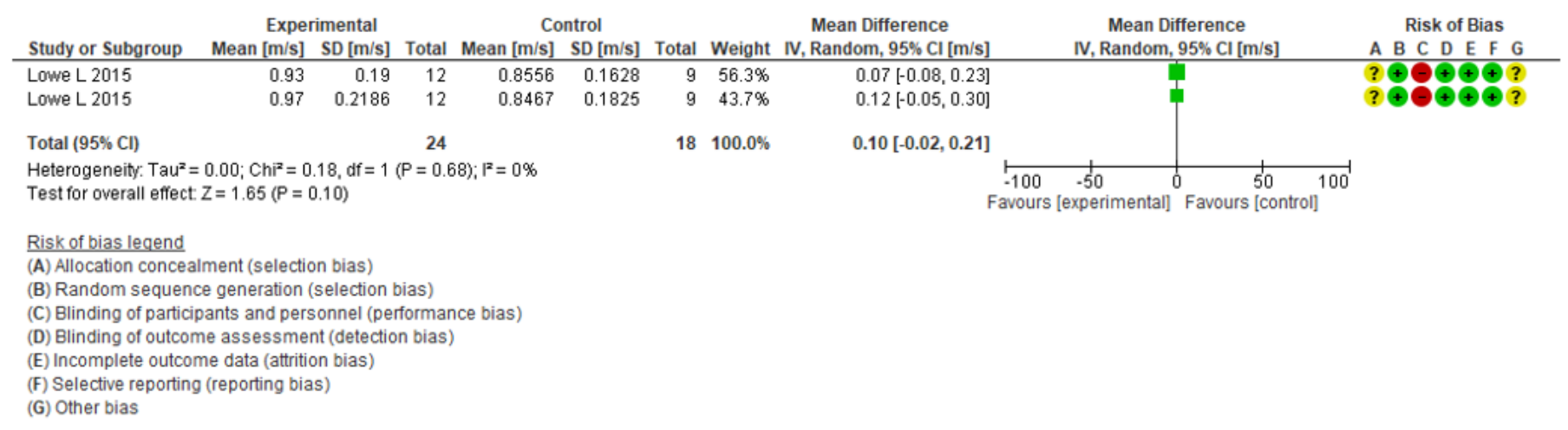

\section{Figure 5}

Aerobic exercise (treadmill) versus control (physiotherapy plan) outcome: gait speed, measurement unit (m/s), and follow-up (4 weeks and 6 weeks).

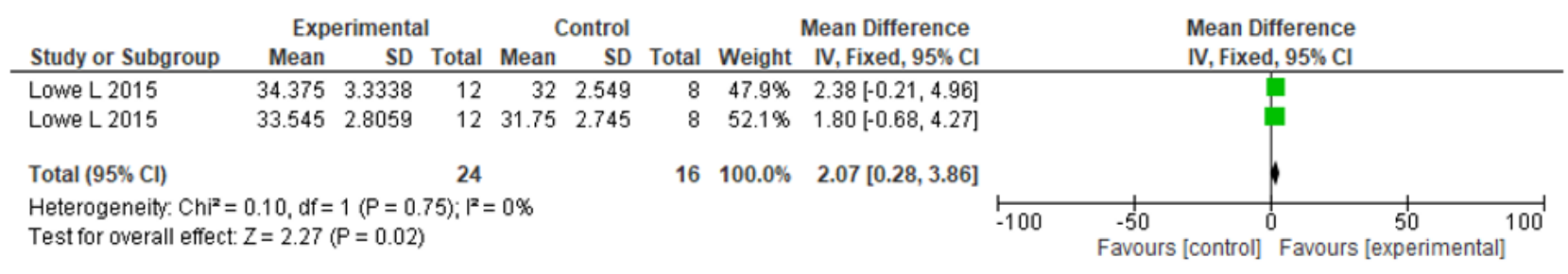

\section{Figure 6}

Aerobic exercise (treadmill) versus control (physiotherapy plan-outcome: motor development (GMFM scale) follow-up (4 weeks and 6 weeks). 